\title{
Ethylene Carbonate-Free, Adiponitrile-Based Electrolytes Compatible with Graphite Anodes
}

\author{
Niloofar Ehteshami ${ }^{\mathrm{a}}$, Elie Paillard ${ }^{\mathrm{a} *}$ \\ a Helmholtz Institute Münster - Forschungszentrum Jülich GmbH (IEK 12), Corrensstr. 46, \\ 48149 Münster, Germany \\ *e.paillard@fz-juelich.de
}

\begin{abstract}
Adiponitrile-based, ethylene carbonate-free electrolytes were investigated for a use in room temperature, $4.5 \mathrm{~V} \mathrm{Li-ion} \mathrm{batteries} \mathrm{including} \mathrm{graphite}$ electrodes. The use of DMC as co-solvent in a 1/1, (wt/wt) ratio and the incorporation of lithium bis(fluorosulfonyl)imide (LiFSI) and lithium difluorooxalatoborate (LiDFOB) anions allows reaching conductivities of $5.8 \mathrm{~ms} \mathrm{~cm}-1$ and $3.4 \mathrm{mS} \mathrm{cm}^{-1}$ at $20^{\circ} \mathrm{C}$, respectively. Electrochemical stability windows of more than $5.0 \mathrm{~V}$ were obtained with both salts. The cycling of graphite electrodes of c.a. $7.5 \mathrm{mg} \mathrm{cm}^{-2}$ is demonstrated with LiDFOB, even without the use of SEI additives, given the SEI-forming properties of the salt. The addition of fluoroethylene carbonate allows improving further the electrolyte performance to $99.9 \%$ efficiency. As for cathode operation, cycling of $15 \mathrm{mg} \mathrm{cm}^{-2} \mathrm{LiNi}_{0.33} \mathrm{Mn}_{0.33} \mathrm{Co}_{0.33} \mathrm{O}_{2}$ was achieved in the $3 \mathrm{~V}-4.5 \mathrm{~V}$ potential range $\left(\mathrm{Vs} \mathrm{Li}^{+} / \mathrm{Li}\right)$ with only a $0.2 \%$ capacity decay per cycle.
\end{abstract}

\section{Introduction}

Increasing the energy density of Li-ion batteries to push further their application for powering electric vehicle implies, at the material level, increasing either the electrodes capacity or the battery (i.e. cathode) operating voltage. However, the limiting factor for operating cathodes at high voltage, be them NMC above 4.3[1], or LiMn1.5Ni0.5O4 up to 4.8V - 5.0V, is the limited anodic stability of state-of-the-art alkyl carbonates-based electrolytes. Thus, the use of alternative solvents such as alkyl-sulfone, ionic liquids, fluorinated alkylcarbonates has been proposed[2].

Among them, aliphatic alkyl dinitrile $\left(\mathrm{CN}\left(\mathrm{CH}_{2}\right)_{n} \mathrm{CN}, \mathrm{n}=3-8\right)$, and adiponitrile ( $\left.\mathrm{ADN}, \mathrm{n}=4\right)$ in particular, offer high anodic stabilities[3,4]. However, the preparation of high-energy Li-ion cells requires, in most cases, the use of graphite-based anodes. Thus, solutions have to be found for the operation of graphite electrodes, given their insufficient cathodic stability and poor ability to form solid electrolyte interphase (SEI) [5,6] at the surface of graphite, which is a prerequisite for it suse a Li-ion anode..

In fact, using EC as co-solvent in ADN-based electrolytes allowed the cycling of either full graphite/LiCoO 2 cells or graphite half-cells with either LiTFSI [3] or $\mathrm{LiBF}_{4}$ [7]. However, EC is considered responsible for both the poor low temperature performance of the electrolytes[8] and their failure at high voltage[1] and efforts have thus been directed toward EC-free electrolytes as well. Gmitter et al. [8], in particular, demonstrated successful cycling of $\mathrm{MCMB} / \mathrm{LiCoO} 2$ cells, by 
using VC or FEC as additives and $\mathrm{LiBF}_{4}$ as a co-salt for a LiTFSI/ADN-based electrolyte. However, as MCMB are known for allowing the use of PC-based electrolytes, which are usually incompatible with graphite[9], the possibility of operating graphite anodes with adiponitrile, ECfree electrolytes have not been demonstrated up to now.

In fact, the low solubility of typical inorganic salts such as $\mathrm{LiPF}_{6}$ and $\mathrm{LiBF}_{4}$ in pure alkyl dinitriles initially led toward the use of LiTFSI[3], a salt with high thermal and electrochemical stability and low lattice energy. However, this salt does not possess intrinsic SEI forming ability (when used as single salt in the electrolyte) and it induces Al current collector corrosion. However, other salts, such as lithium difluorooxalatoborate (LiDFOB) and lithium bis(fluorosulfonyl)imide (LiFSI) are good candidates for substituting $\mathrm{LiPF}_{6}$ as they provide enhanced SEI forming ability in various type of electrolytes. In addition, they are usually more soluble in organic solvents, including those with lower dissociating properties than typical EC mixtures. Thus, we report here on the electrochemical characterizations of EC-free electrolytes based on ADN:DMC mixtures with $\mathrm{LiDFOB}$ or $\mathrm{LiFSI}$, for a use in $4.5 \mathrm{~V}$, graphite-based, Li-ion batteries at room temperature.

\section{Experimental part}

Electrolyte preparation: ADN (Aldrich, 99\%) was distilled under vacuum and dried on molecular sieve at room temperature until the water content dropped below $20 \mathrm{ppm}$ as determined by coulometric Karl-Fischer titration (KF 851 Titrando, Mettler Toledo). Dimethyl carbonate (DMC) (BASF, Selectilyte ${ }^{\mathrm{TM}}$ ) and fluoroethylene carbonate (FEC) (BASF, Selectilyte ${ }^{\mathrm{TM}}$ ) were used as received. The lithium salts were either used as received $\left(\mathrm{LiPF}_{6}\right.$ (BASF, Selectilyte ${ }^{\mathrm{TM}}$, 99.99\%)) or dried under vacuum for $48 \mathrm{~h}$ at $80^{\circ} \mathrm{C}$ for LiDFOB (Aldrich), and $90^{\circ} \mathrm{C}$ for LiFSI (PROVISCO CZ). Electrolyte solutions were prepared and stored in a Mbraun glove box filled with $\operatorname{argon}\left(<1 \mathrm{ppm} \mathrm{H}_{2} \mathrm{O} \& \mathrm{O}_{2}\right)$.

Electrode preparation: Graphite electrode of $96 \mathrm{wt} \%$ active mass loading and $7.5 \mathrm{mg} \mathrm{cm}-2$ were provided by CEA-LITEN (France). $\mathrm{LiNi}_{0.33} \mathrm{Mn}_{0.33} \mathrm{Co}_{0.33} \mathrm{O}_{2}$ electrodes of $86 \mathrm{wt} \%$ active mass loading and $15 \mathrm{mg} \mathrm{cm}^{-2}$ were purchased from Custom Cells (Germany) and used as received

Electrochemical testing: All electrochemical testing was done in 3 electrode Swagelok ${ }^{\mathrm{TM}}$ cells assembled in a glove box (MBraun) with $\mathrm{O}_{2}$ and $\mathrm{H}_{2} \mathrm{O}$ level below $1 \mathrm{ppm}$ with Li counter and reference electrodes (99.99\%, Rockwood lithium) using a stack of 6 layers of Freudenberg FS2026 non-woven poylpropylene separator drenched with $200 \mu \mathrm{l}$ of electrolyte. Voltamperometries were performed on a VMP3 (Bio-logic) potentiostat-galvanostat and cycling was done on a Maccor 4300 with cells placed in a temperature controlled chamber (KB400, Binder $\mathrm{GmbH})$ at $20^{\circ} \mathrm{C}$. Conductivities were measured using a, impedance-based conductimeter (MCS10, Bio-Logic) between $-60^{\circ} \mathrm{C}$ and $25^{\circ} \mathrm{C}$ using a steps of $5^{\circ} \mathrm{C}$ with 20 minutes ramps in between each steps $5^{\circ} \mathrm{C}$ per step going from high to low temperature. The electrodes were charged using a constant current step at $\mathrm{C} / 10$ for the first two cycles and $\mathrm{C} / 2$ for the following cycles, followed by a constant voltage step using a $\mathrm{C} / 50$ current limit. A Full-cell was assembled using the same electrodes and cycled in two electrode configuration with similar cycling protocol, excepted for the constant voltage step at the cut-off voltage during charge.

\section{Results and discussion}




\subsection{Conductivity of the electrolytes}

The conductivity curves of the $1 \mathrm{M}$ ADN/DMC (1/1, wt/wt) electrolytes are shown in Figure 1. It is worth mentioning that the $1 \mathrm{M} \mathrm{LiPF}_{6}$ electrolyte was not liquid at room temperature, but had the appearance of a gel-like paste, probably due to insufficient solubility of LiPF6 or to the formation of solid $\mathrm{LiPF}_{6} /$ solvent complexes. Accordingly, the conductivity curve has an irregular shape with several transitions. The conductivities stays well below those of the two other salts tested with only c.a. $1 \mathrm{mS} \mathrm{cm}^{-1}$ at $20^{\circ} \mathrm{C}$. For LiFSI, a conductivity of $5.8 \mathrm{mS} \mathrm{cm}^{-1}$ is reached at $20^{\circ} \mathrm{C}$ while that of LiDFOB is lower at $3.3 \mathrm{mS} \mathrm{cm}^{-1}$. For comparison, the conductivity of the $1 \mathrm{M}$ lithium bis(trifluoromethanesulfonyl)imide (LiTFSI) $+0.1 \mathrm{M}$ lithium bis(oxalate) borate (LiBOB) and $1 \mathrm{M} \mathrm{LiBF}_{4}+0.1 \mathrm{M} \mathrm{LiBOB}$ in EC:ADN $(1 / 1, \mathrm{v} / \mathrm{v})$ are $3.6 \mathrm{mS} \mathrm{cm}^{-1}[10]$ and $2.1 \mathrm{mS} \mathrm{cm}^{-1}$ [4] respectively. The LiFSI electrolyte stayed liquid until $-20^{\circ} \mathrm{C}$ before crystallizing, which is on the curve as as a strong conductivity drop. The LiDFOB electrolyte start partially crystallizing between $-5^{\circ} \mathrm{C}$ and $-10^{\circ} \mathrm{C}$, which translates to a deviation to the Vogel-Tammann-Fulcher (VTF) behavior below this point with a further crystallization occurring below $-20^{\circ} \mathrm{C}$ which induces a stronger conductivity drop.

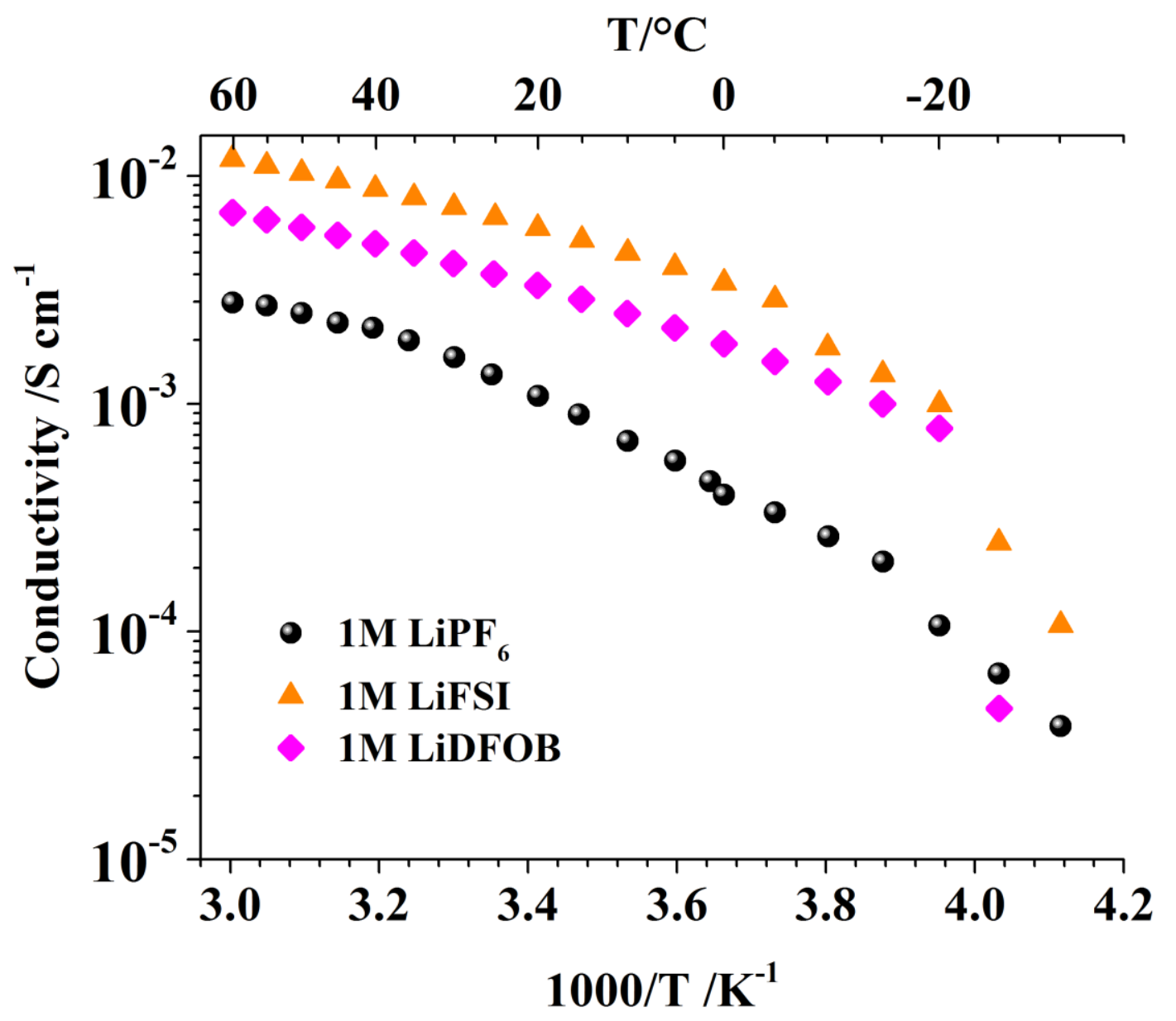

Figure 1: Conductivity plot of the $1 \mathrm{~m} \mathrm{ADN/DMC} \mathrm{(1/1,wt/wt)} \mathrm{electrolytes}$ 


\subsection{Electrochemical stability windows}

Figure 2 shows the voltamperograms of the $1 \mathrm{M}$ electrolytes electrochemical stability window for the $1 \mathrm{M}$ ADN/DMC electrolytes. In reduction, only low background currents between 7 and $11 \mu \mathrm{A} \mathrm{cm}^{-2}$ are observed before Li metal plating occurs, probably due to electrode passivation. On the anodic scan, the two electrolytes containing FEC exhibit similar decomposition potential at c.a. 5.5V. The LiFSI, FEC-containing electrolyte exhibits the strongest background oxidation current, which, however, does not raise above $5 \mu \mathrm{A} \mathrm{cm}^{-2}$ even in this case. The LiDFOB electrolyte without additive decomposes at lower potential, at c.a. $5.2 \mathrm{~V}$.

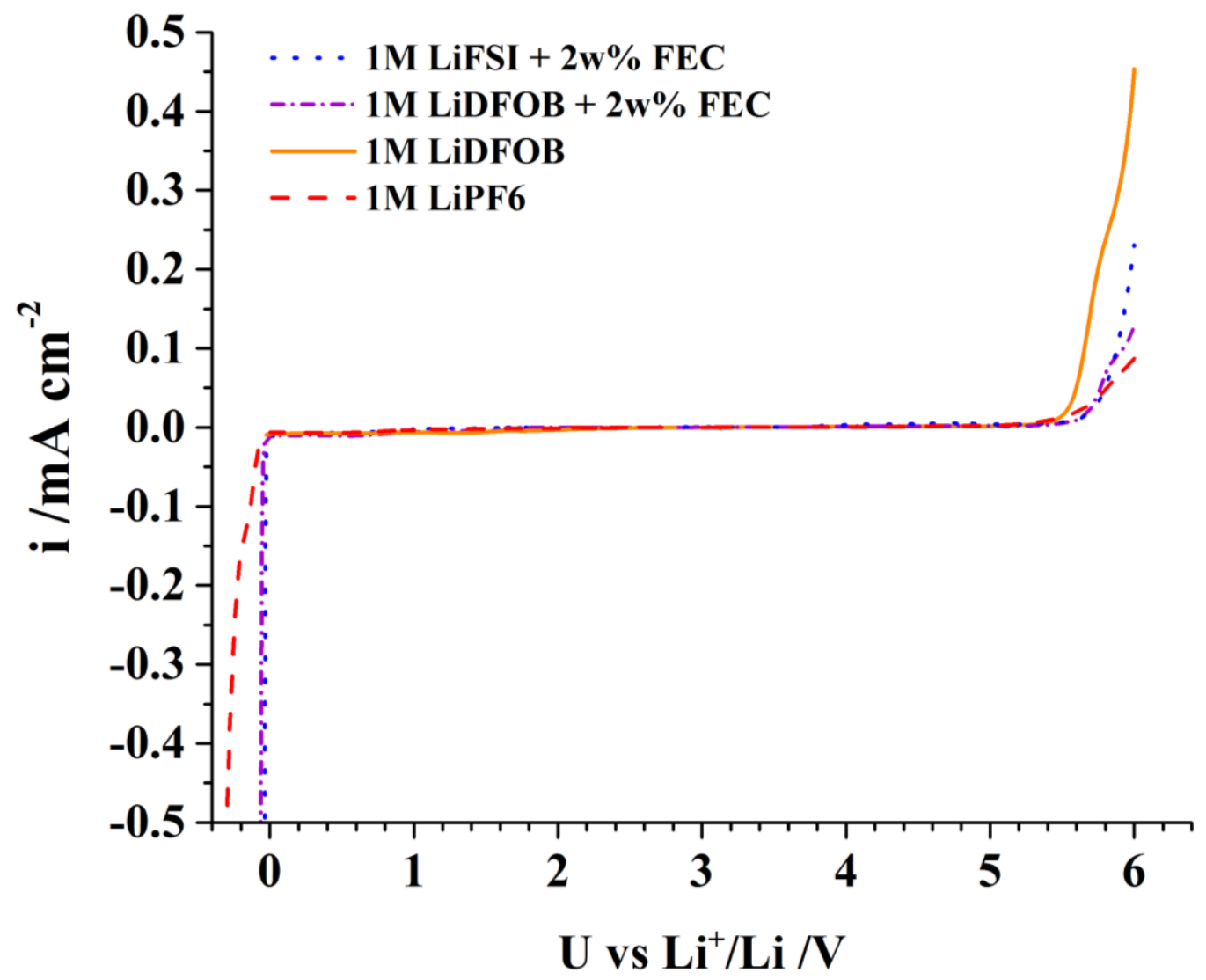

Figure 2: Voltamperogram of $1 \mathrm{M}$ ADN/DMC (1/1, wt/wt) electrolytes at $0.1 \mathrm{mV} \mathrm{s} \mathrm{s}^{-1}$. WE: Pt (anodic scan) and Ni (cathodic scan), RE \& CE: Li

\subsection{Graphite electrode cycling}

Figure 3a. shows the cycling performance of standard high mass loading graphite electrodes in $1 \mathrm{M}$ LiDFOB ADN/DMC electrolytes with and without the addition of $2 \mathrm{wt} \%$ FEC as SEI forming additive. The efficiencies in the first cycles are rather high in both cases, with respectively $90.4 \%$ and $92.2 \%$. It is remarkable, considering the absence of EC as solid electrolyte (SEI) forming co-solvent. The efficiencies then raise above $99.9 \%$ for the FEC containing electrolyte, whereas those of the additive-free electrolyte stays lower and only reach $99.7 \%$. It is possible that, in half cells, especially with high mass loading electrodes, the Li metal electrode influences the efficiency results, as FEC might as well favor quick SEI formation/reformation at the counter 
electrode as well and limit shuttling of electrolyte reduction products to the cathode. The capacity retention is rather high in both cases with, however, an advantage for the FEC containing electrolyte.

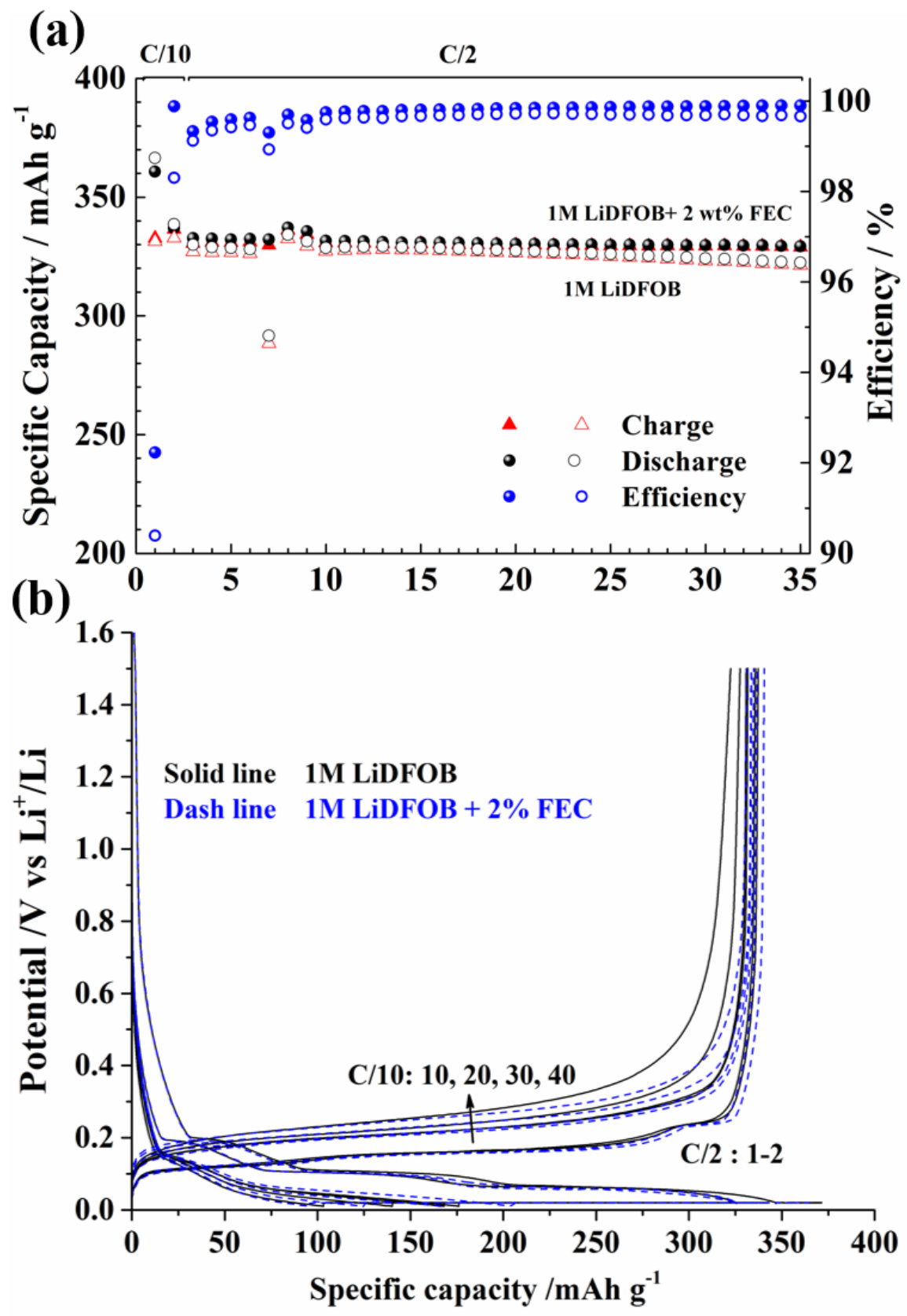

Figure 3: Graphite electrodes $7.5 \mathrm{mg} \mathrm{cm}^{-2}$ cycled in 3 electrode cells in 1M LiDFOB, ADN/DMC $(1 / 1, w t / w t)$ with or without FEC (a) Comparison of cycling stability and efficiency (b) Comparison of voltage profiles for selected cycles $\left(1 \mathrm{C}=372 \mathrm{~mA} \mathrm{~g}^{-1}\right)$

As can be seen on the potential profiles, shown in figure $3 \mathrm{~b}$, the lithium insertion and de-insertion plateaus are well defined at $\mathrm{C} / 10$ for both electrolytes, but at C/2, only c.a. $175 \mathrm{mAh} \mathrm{g}^{-1}$ are inserted during the constant current step in the $3^{\text {rd }}$ cycle. Because of the higher ohmic drop, only the two first insertion plateau are then seen upon lithium insertion In addition, over cycling, the voltage 
profiles evolves with more marked ohmic drops. While in the case of the electrolyte without FEC, the slope during de-insertion becomes more marked, due to $\mathrm{Li}^{+}$transport limitation by diffusion, in the case of the FEC-containing electrolyte, mainly a ohmic drop effect is seen and the curves remain relatively parallel to each other's upon cycling. It probably results from a better SEI formation on the surface of graphite in the FEC-containing electrolyte (i.e. a more protective and thinner SEI in which limited diffusion occurs and which does not lead to as much accumulation of degradation products on its outer layer upon cycling). In the case of the FEC-free electrolyte, although a SEI forms and allows graphite operation, it is probably less protecting and grows over time, which could explain the increase $\mathrm{Li}^{+}$transport limitations over cycling (electrode clogging) and would be consistent with the lower efficiencies observed. On the other hand, increased ohmic drop could simply be a result of electrolyte consumption at the Li counter electrode (even in 3 electrode cell configuration, as the reference electrode is placed in between the graphite electrode and the counter electrode, half of the ohmic drop linked to the electrolyte resistance is still seen on the potential profiles).

\subsection{Cycling of $\mathrm{LiNi}_{0.33} \mathrm{Mn}_{0.33} \mathrm{Co}_{0.33} \mathrm{O}_{2}$ up to $4.5 \mathrm{~V}$}

Figure $4 \mathrm{a}$. shows the cycling stability of a commercial $7.5 \mathrm{mg} \mathrm{cm}^{-2}$ standard NMC electrode in $1 \mathrm{M}$ LiDFOB ADN/DMC + $2 \mathrm{wt} \%$ FEC. As can be seen, the capacity retention at $\mathrm{C} / 2$ is rather good with only a $0.2 \%$ decay per cycle at $\mathrm{C} / 2$, although the capacity cycled at $\mathrm{C} / 2$ is somewhat low, as compared to what can be reached in conventionnal $1 \mathrm{M} \mathrm{LiPF} 6$ EC/DMC electrolyte. The corresponding voltage profiles are shown on figure 4.b and show that the ohmic drop at the beginning of the charge decreases between the first and second cycle, but then increases. As this corresponds to Li plating step, it is likely that 


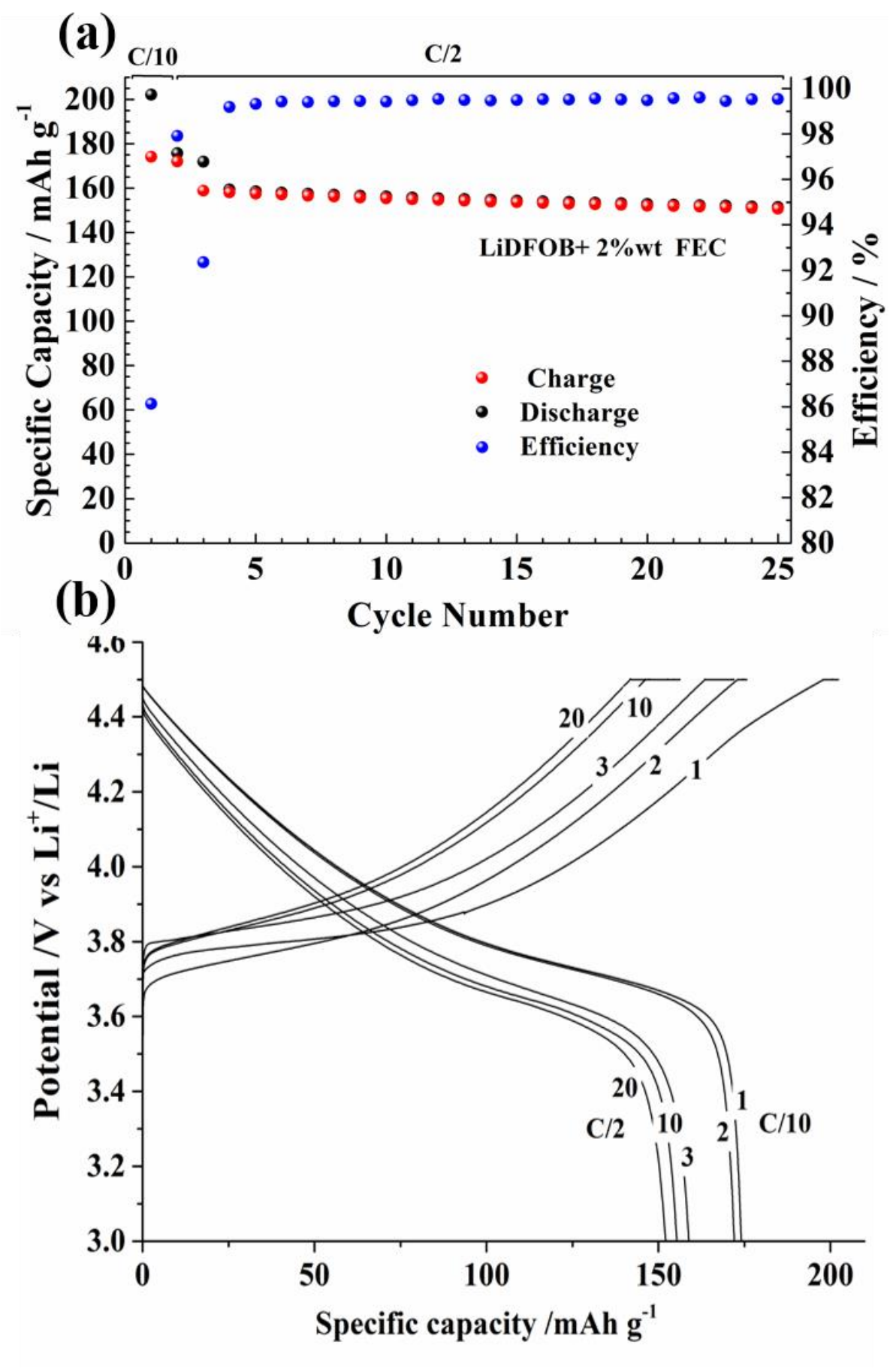

Figure 4: NMC electrodes cycled in half-cell in 1M LiDFOB with $2 \mathrm{w} \%$ FEC, ADN/DMC (1/1, wt/wt), cycling stability and efficiency

\subsection{Graphite/NMC full cell}

To confirm the role of Li metal counter electrode, a full cell was assembled, usingthe same electrodes (i.e. not balanced for full cell at $4.5 \mathrm{~V}$ ) and the voltage profiles at $\mathrm{C} / 10$ and $\mathrm{C} / 2$ are shown in figure 5. As can be seen, the charged at $\mathrm{C} / 2$ is, in this case much closer to that at $\mathrm{C} / 10$, with only 
limited increase of ohmic drop at the beginning of the first charge at $\mathrm{C} / 2$ and similar charged capacities as at $\mathrm{C} / 10$, which shows that the lithium metal electrode does affect the ohmic drop significantly. Unfortunately, at $\mathrm{C} / 2$, Li plating occurs upon charge, as seen upon discharge by the location of the first graphite plateau, which is which is detrimental for cycling stability and result into a lowering of overvoltage during the first charge at $\mathrm{C} / 2$.

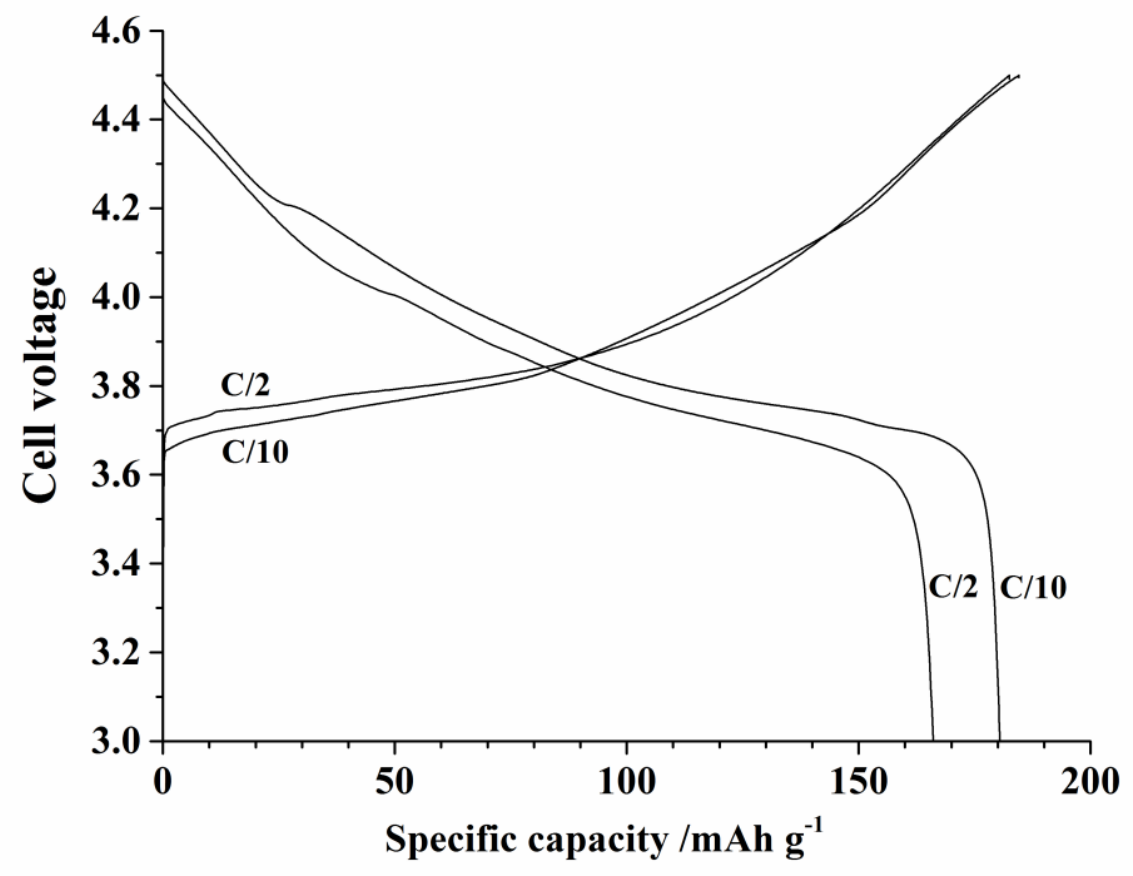

Figure 5: Voltage profile of a Graphite/NMC full cell at $\mathrm{C} / 10$ ( $2^{\text {nd }}$ cycle) and $\mathrm{C} / 2$ ( $3^{\text {rd }}$ cycle). Specific capacity refers to the cathode.

\section{Conclusion}

The conductivities and electrochemical stability window of AND/DMC electrolyte containing $1 \mathrm{M}$ LiFSI and or LiDFOB have been measured to be in the range of commercial li-ion electrolytes for LiFSI and slightly lower for LiDFOB. The LiDFOB electrolyte as been shown to allow graghite cycling with and without the addition of FEC as SEI forming additive and cycling efficiencies above $99.9 \%$ have been achieved with the use of FEC as well as stable capacities, using a constant voltage step. However, in half-cells, lithium insertion is slow and only a fraction of the full graphite capacity can be reached at $\mathrm{C} / 2$ during lithium insertion. Cycling of NMC cathode was also possible with a $0.2 \%$ capacity decay per cycle. A full-cell was assembled to asses the influence of the $\mathrm{Li}$ metal electrode in half cells and it was found that, although the cathide is oveerdimensionned, the ohmic drop at the beginning of charge is reduced in this case, although lithium platig occurs before the end of the charge and result in short cycle life in the following cycles. While this result are preliminary, the composition of the SEI formed on graphite in the absence of EC deserves further investigations.

\section{Acknowledgement:}


The research presented is part of the 'SPICY' project funded by the European Union's Horizon 2020 research and innovation program under grant agreement $\mathrm{N}^{\circ}$ 653373. CEA-LITEN and Dr. Willy Porcher is gratefully acknowledged for providing the graphite electrodes.

\section{References:}

[1] J. Xia, R. Petibon, D. Xiong, L. Ma, J.R. Dahn, Enabling linear alkyl carbonate electrolytes for high voltage Li-ion cells, J. Power Sources. 328 (2016) 124-135. doi:10.1016/j.jpowsour.2016.08.015.

[2] K. Xu, Electrolytes and Interphases in Li-Ion Batteries and Beyond, Chem. Rev. 114 (2014) $11503-11618$.

[3] Y. Abu-Lebdeh, I. Davidson, High-Voltage Electrolytes Based on Adiponitrile for Li-Ion Batteries, J. Electrochem. Soc. 156 (2009) A60. doi:10.1149/1.3023084.

[4] H. Duncan, N. Salem, Y. Abu-Lebdeh, Electrolyte Formulations Based on Dinitrile Solvents for High Voltage Li-Ion Batteries, J. Electrochem. Soc. 160 (2013) A838-A848. doi:10.1149/2.088306jes.

[5] E. Peled, The Electrochemical Behavior of Alkali and Alkaline Earth Metals in Nonaqueous Battery Systems - The Solid Electrolyte Interphase Model, J. Electrochem. Soc. 126 (1979) 2047. doi:10.1149/1.2128859.

[6] J.R. Fong, R. von Sacken U. Dahn, Studies of Lithium Intercalation into Carbons Using Nonaqueous Electrochemical Cells, J. Electrochem. Soc. 137 (1990) 2009-2013.

[7] P. Isken, C. Dippel, R. Schmitz, R.W. Schmitz, M. Kunze, S. Passerini, et al., High flash point electrolyte for use in lithium-ion batteries, Electrochim. Acta. 56 (2011) 7530-7535. doi:10.1016/j.electacta.2011.06.095.

[8] A.J. Gmitter, I. Plitz, G.G. Amatucci, High Concentration Dinitrile, 3-Alkoxypropionitrile, and Linear Carbonate Electrolytes Enabled by Vinylene and Monofluoroethylene Carbonate Additives, J. Electrochem. Soc. 159 (2012) A370. doi:10.1149/2.016204jes.

[9] D. Aurbach, E. Zinigrad, Y. Cohen, H. Teller, A short review of failure mechanisms of lithium metal and lithiated graphite anodes in liquid electrolyte solutions, Solid State Ionics. 148 (2002) 405-416. doi:10.1016/S0167-2738(02)00080-2.

[10] A. Abouimrane, I.J. Davidson, Solid Electrolyte Based on Succinonitrile and LiBOB, J. Electrochem. Soc. 154 (2007) A1031. doi:10.1149/1.2781305. 